\title{
The in vivo Three-dimensional Form of a Plant Mycoplasma-like Organism by the Analysis of Serial Ultrathin Sections
}

\author{
By HENRY WATERS ${ }^{1}$ AND PETER HUNT ${ }^{2 *}$ \\ ${ }^{1}$ Coconut Industry Board, P.O. Box 204, Kingston 10, Jamaica \\ ${ }^{2}$ Botany Department, University of the West Indies, Kingston 7, Jamaica
}

(Received 24 April 1979)

\begin{abstract}
Mycoplasma-like organisms (MLO) associated with lethal yellowing disease of coconut palms exhibited a range of different morphologies even within the same sieve element. The morphologies were revealed by graphic reconstruction from ribbons of serial ultrathin sections containing 45 sections. Five different morphotypes were recognized amongst the 120 organisms reconstructed. MLO could be saccate, erythrocyte-like, cylindrical, moniliform or filiform. The different morphotypes showed differences in linear dimensions apart from their particular morphological characteristics. Saccate MLO were generally the smallest, the maximum length being $1 \mu \mathrm{m}$, whilst the filiform organisms could be more than $16 \mu \mathrm{m}$ long. The morphologies of the MLO were analogous to those now recognized as usual for Mycoplasma and Acholeplasma species in vitro during the later stages of development. Comparison of the individual profile shapes used in the reconstructions with those of MLO from other diseased plants suggest that many previous interpretations of MLO morphology may have been too simple. With the insight provided by the understanding of the relationship between profile shape and three-dimensional form, the ultrastructure of individual profiles is shown to be an important indicator of form.
\end{abstract}

\section{INTRODUCTION}

Observations of intact mycoplasmas taken from culture show that although they occur most frequently as simple spheres or filamentous bodies they are capable of becoming freely branched or even giving rise to mycelial complexes (Razin, 1978; Tully, 1978). Other modifications of form, such as rings and beaded chains, have also been described. The elucidation of morphology in vitro began nearly 70 years ago but the exceptionally detailed light microscopic studies of Turner (1935) provide some of the best early illustrations. More recently, the use of similar or more sophisticated techniques has generally confirmed these early studies despite some controversy over the manner of reproduction and the significance of the numerous biological and physical factors which are known to affect form (Freundt, 1960, 1969; Anderson, 1969; Boatman \& Kenny, 1971; Bernstein-Ziv, 1971; Lemcke, 1972; Boatman, $1973 a$; Robertson et al., 1975a). Since 1972 (Davis et al., 1972) helical prokaryote mollicutes have been recognized and this morphology is now regarded as one of the characteristics of the so far monotypic genus Spiroplasma (Saglio et al., 1973).

Phloem-restricted micro-organisms, having the ultrastructural (Horne, 1972) and antibiotic sensitivity characteristics of mollicute organisms, have been implicated in causing more than 80 different plant diseases since their discovery by Doi et al. (1967). Such mycoplasma-like organisms (MLO) have been associated with coconut lethal yellowing following the observation of MLO in the sieve elements of diseased coconut palms (PlavsicBanjac et al., 1972; Beakbane et al., 1972; Parthasarathy, 1974) and the remission of

* Present address: LPTI Sub-Station, P.O. Box 1, Solok, Sumatera, Barat, Indonesia. 
symptoms after treatment with tetracycline antibiotics (McCoy, 1972; Hunt et al., 1974).

The taxonomic position of the MLO is uncertain since, with the exception of the spiroplasmas, they have yet to be reproducibly cultivated in vitro. It follows that any description of MLO morphology must therefore derive from organisms studied in vivo.

It is not possible to extract MLO from a living host without inducing artifacts either on extraction or during observation when the organisms are prey to the same biological and physical factors that produce changes in the morphology of mycoplasmas grown in vitro. Even if precautions are taken to minimize artifacts the interpretation of MLO morphology in the sap expressed from diseased plants is impossible because the extracted organisms cannot be reliably differentiated from a background of cell debris (Wolanski \& Maramorosch, 1970; Wolanski, 1973). It has therefore been necessary to deduce mycoplasmal and MLO morphology in vivo from the shape of profiles in ultrathin sections. These two-dimensional profiles have been interpreted, almost without exception, in terms of the simplest plausible three-dimensional form. Similarly, where cultured mycoplasmas have been visualized in section, a simple interpretation has also been placed on them despite evidence that in vitro the intact organisms are frequently complex in form.

Clearly it is important to understand how profile shape relates to the intact form of MLO and mycoplasmas. This has been achieved for Spiroplasma citri and several other spiroplasmas (Davis \& Worley, 1973; Cole et al., 1973; Markham et al., 1974). In their plant hosts, the helical form of spiroplasmas is readily recognized in ultrathin or thick ultramicrotome sections by the regular spacing of profiles associated with a sectioned helix. Mycoplasmas and MLO on the other hand present, in similar sections, irregularly spaced profiles of variable size which may be circular, elliptical, sausage-shaped, filamentous or even dumbbell-shaped.

In an attempt to resolve some of the inconsistencies in previous interpretations of MLO morphology we prepared ribbons of ultrathin sections of roots from coconut palms affected by lethal yellowing and in this paper we describe the morphology of the MLO associated with lethal yellowing. We also discuss how three-dimensional form may sometimes be deduced from only a few serial sections once the shapes and ultrastructure of organisms in individual sections can be related to morphology. The understanding that this morphological study of an MLO provides also gives an insight into the threedimensional form of mycoplasmas when these are studied in ultrathin sections and emphasizes the morphological affinities between the mycoplasmas and MLO. A preliminary announcement of these findings has been made (Waters \& Hunt, 1978).

\section{METHODS}

Specimen preparation. Portions of tertiary roots 2 to $3 \mathrm{~cm}$ long and approximately $1 \mathrm{~mm}$ in diameter were removed in the field from a palm affected by lethal yellowing. The samples were immediately immersed in a buffer ( $\mathrm{pH} \mathrm{7.2)} \mathrm{containing} 0.05 \mathrm{M}$-sodium cacodylate, $0.15 \mathrm{M}$-sucrose and $2 \mathrm{~mm}$-calcium chloride to which glutaraldehyde and paraformaldehyde were added to final concentrations of $3 \%(v / v)$ each. By freezing point determinations the osmolarity of the buffer was estimated to be 250 mosmol. Primary fixation was for $3 \mathrm{~h}$ at ambient temperatures of approximately $30^{\circ} \mathrm{C}$ and subsequent procedures were carried out at about $21^{\circ} \mathrm{C}$. After primary fixation the samples were rinsed overnight in three changes of buffer. Post-fixation for $2 \mathrm{~h}$ in $2 \%(\mathrm{w} / \mathrm{v})$ osmium tetroxide in buffer preceded a further overnight buffer rinse. The samples were trimmed at this stage to the middle $5 \mathrm{~mm}$ and the terminal portions were discarded. A longitudinal split was made in the trimmed roots to ensure effective resin impregnation. Prior to dehydration through an ascending acetone series the samples were immersed in $1 \%(\mathrm{w} / \mathrm{v})$ aqueous uranyl acetate for $3 \mathrm{~h}$. Embedding was carried out using Spurr's resin (Spurr, 1969).

Serial sections, cut with a diamond knife on an LKB Ultratome III, were mounted supported by Formvar on a special serial section holder for an AEI 801A electron microscope. Contrast was enhanced with $20 \%(\mathrm{w} / \mathrm{v})$ methanolic uranyl acetate and lead citrate (Venable \& Coggershall, 1965).

Analysis of serial sections. From one series of 45 serial transverse ultrathin sections, two mature MLOcontaining sieve elements were selected for study. Electron micrographs at $50000 \times$ magnification were 
prepared for all the sections of each cell. Individual section thickness was estimated to be between 70 and $80 \mathrm{~nm}$ based upon the interference colour of the sections when floating on the knife water bath (Reid, 1974). Each set of 45 micrographs therefore represented a length of approximately $3.5 \mu \mathrm{m}$. To study the largest number of complete MLO, analysis was carried out beginning with the middle, i.e. the 23rd, section of each series. Each MLO profile in these middle electron micrographs was followed as it related to profiles in successive adjacent micrographs until the individually identified organisms either terminated or extended beyond the series. The analysis was difficult to achieve because it was necessary to maintain an inventory of the large number of profiles (over 10000 for both cells) in the sections. This difficulty was overcome by using tracings made from the electron micrographs which were placed in register. Inspection of the sequence of tracings, with each organism identified, provided an impression of morphology. In establishing continuity of structure, the original electron micrographs were used in conjunction with the tracings. In the very few instances where continuity was equivocal, we erred on the side of conservatism and did not claim continuity.

Determination of volumes. The volume of an individual MLO was determined by weighing all of its constituent profiles cut from electron micrographs. The weights were then corrected to volumes using a constant calculated from the weights of standard areas of identical photographic paper assuming a section thickness of $75 \mathrm{~nm}$.

Representation of three-dimensional form. Drawings to illustrate the morphology of representative organisms were prepared by staggering and superimposing tracings made directly from serial electron micrographs using a method based on that described by Dunn (1972). For most of the figures presented, the MLO are seen as if viewed from an angle of $45^{\circ}$ to the longitudinal axis of the sieve element, the radial dimensions and the shift between profiles being represented at the same magnification. For some MLO with very large profiles, the stagger between sections has been increased and this results in a $50 \%$ exaggeration in the length of an MLO in proportion to its radial dimensions.

Terminology. In some parts of the text we refer to the 'span' of organisms whilst elsewhere we refer to the 'length' of organisms. These terms are each used with particular emphasis. Span defines the number of sections in which an organism appeared. Length was calculated by multiplying the total number of discrete profiles comprising an organism by the estimated section thickness $(75 \mathrm{~nm})$. Thus, organisms can have lengths greater than the span $(3.5 \mu \mathrm{m})$ of the complete ribbon of serial sections.

\section{RESULTS}

The middle sections of the 45 serial sections for the two sieve elements studied are illustrated in Figs 1 and 2. In these two-dimensional electron micrographs, the range of profile shapes is typical of plant MLO. The majority of profiles also exhibit the ultrastructural detail considered to be characteristic for plant MLO, with ribosomes and a reticulate network of DNA enclosed within a trilamellar membrane (Fig. 3).

In following the continuity of profiles from section to section, it became apparent early in the study that most MLO were aligned with their longitudinal axes parallel with the sieve tubes. It was also apparent that several widely separated profiles in any one section could be part of a single organism implying a complex and often branched structure. Thus, the 111 profiles in cell A (Fig. 1) represent only 78 organisms and, similarly, the 51 profiles in cell B (Fig. 2) represent 42 organisms.

Preliminary inspection showed that each of the MLO identified could be described either as irregularly lobed or filamentous. Further subdivision of these two classes was possible on the basis of more refined morphological criteria. Irregularly lobed organisms were either saccate or erythrocyte-like; the filamentous organisms were cylindrical, moniliform or filiform. Table 1 summarizes the distribution of the five morphotypes between the two cells studied.

\section{Description of morphotypes}

Saccate organisms. These were the simplest organisms recognized and ranged in shape from more or less spherical or ellipsoidal (Figs. $4 a$ and $5 k$ ) to irregularly lobed (Fig. $4 b$, $c, d)$ and were always unbranched. They were infrequent, comprising $7 \%$ of the MLO recognized (Table 1). Profiles typical of an approximately spherical MLO are shown together with a reconstructional drawing in Fig. 5. The continuity of structure is self- 


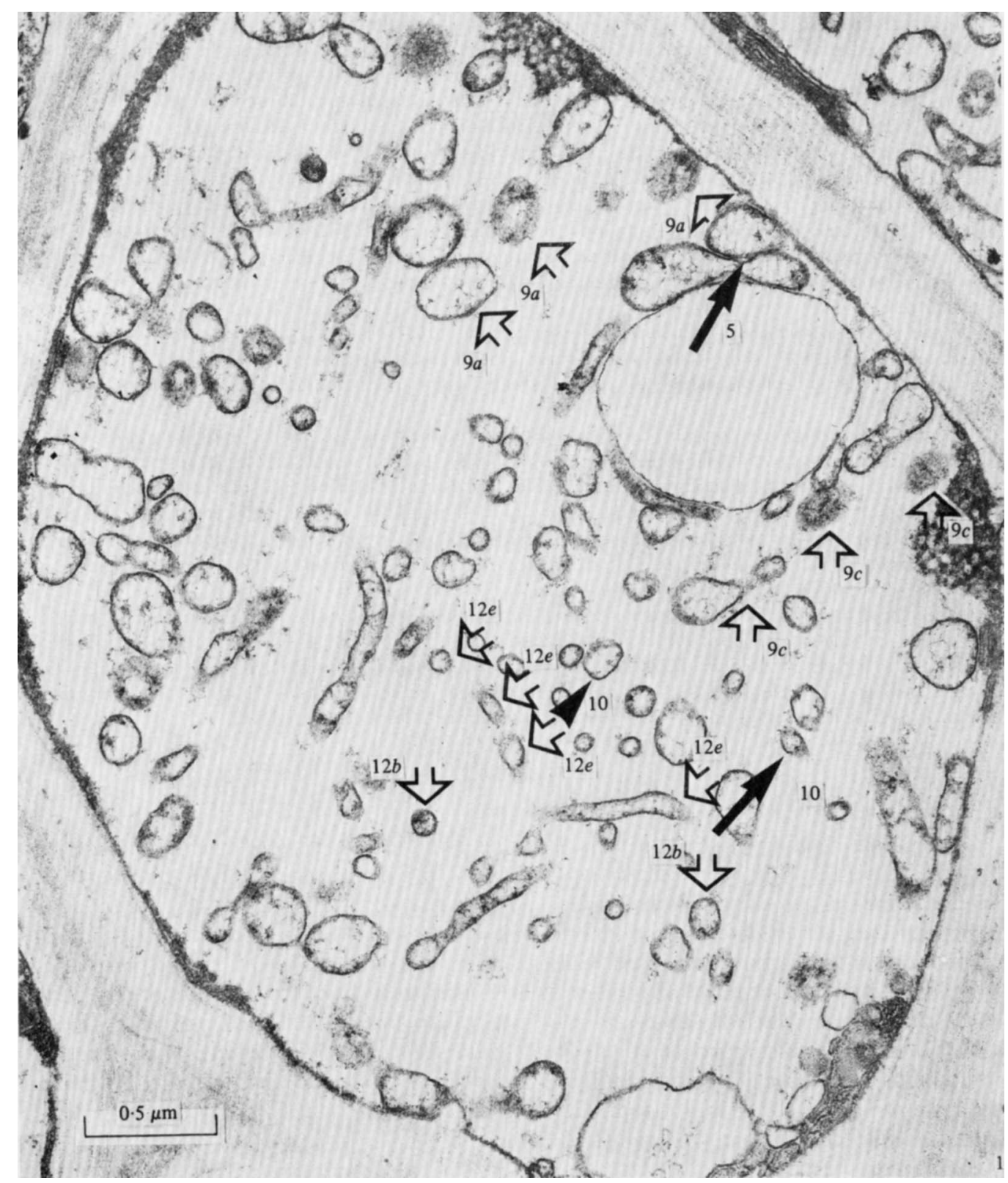

Fig. 1. The middle, i.e. 23rd, section of the 45 section series comprising cell A. The solid arrows indicate organisms which are reconstructed, accompanied by electron micrographs, in the figures indicated. The outline arrows highlight organisms represented as reconstructive drawings in the corresponding figures. All arrows are aligned to show the angle from which the respective organisms are figured.

evident, as are the changes in the more or less circular profile shape associated with the three-dimensional form. It is clear from Fig. 4 that the organisms belonging to this class were not extensive either within the plane of sectioning or perpendicular to it. The dimensions within the plane of sectioning ranged from 130 to $800 \mathrm{~nm}$ and perpendicularly from $375 \mathrm{~nm}$ to approximately $1 \mu \mathrm{m}$. References to linear dimensions for irregularly shaped organisms have little meaning when comparing the sizes of organisms of the same or 

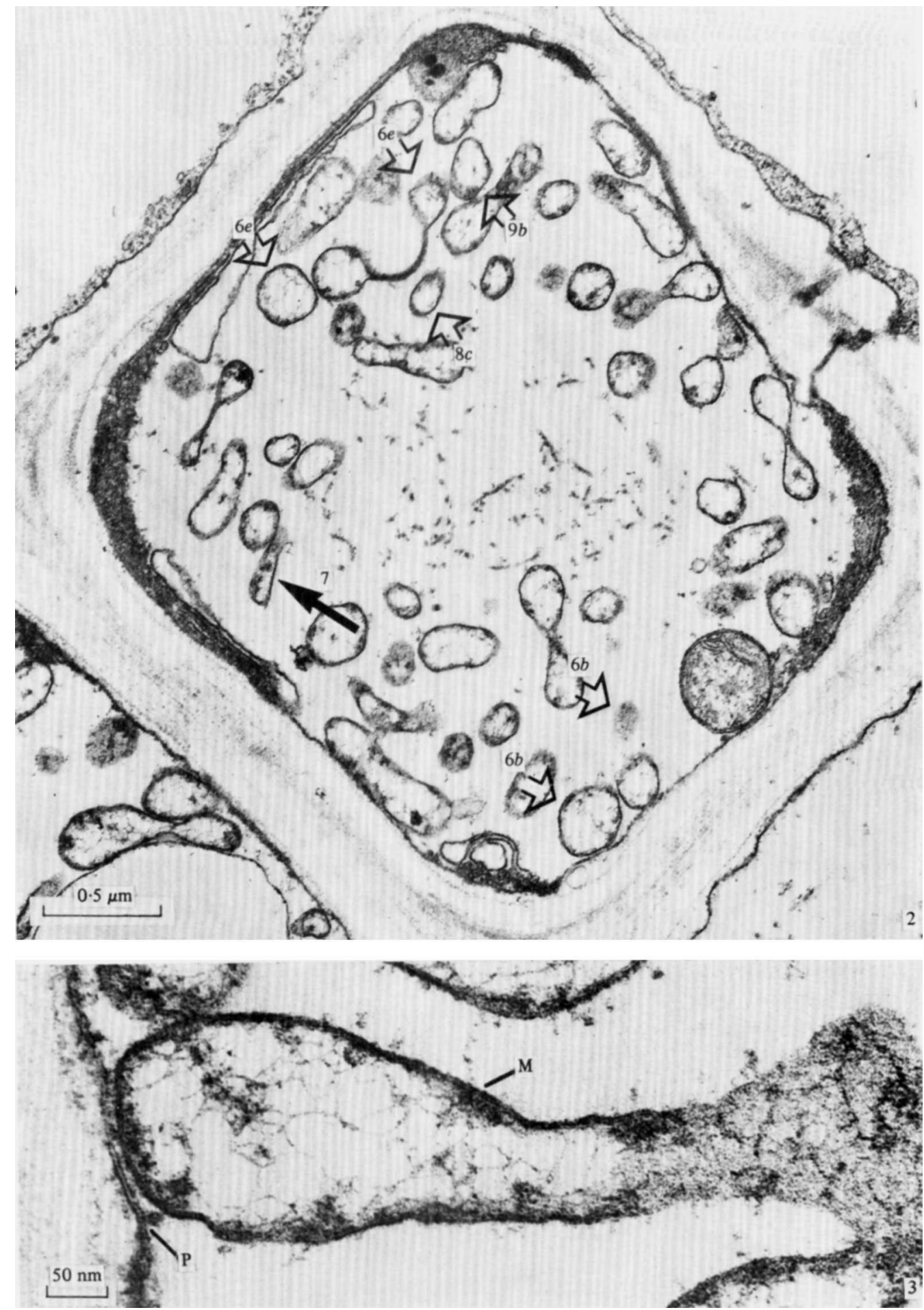

Fig. 2. The middle, i.e. 23rd, section of the 45 section series comprising cell $\mathrm{B}$. The significance of the numbered arrows is explained in the legend to Fig. 1.

Fig. 3. Detail of an MLO profile (one from the MLO in Fig. $9 a$ ) showing the trilamellar membrane (M), DNA material and ribosomes. The plasmalemma of the host sieve element is also shown (P). 
H. WATERS AND P. HUNT

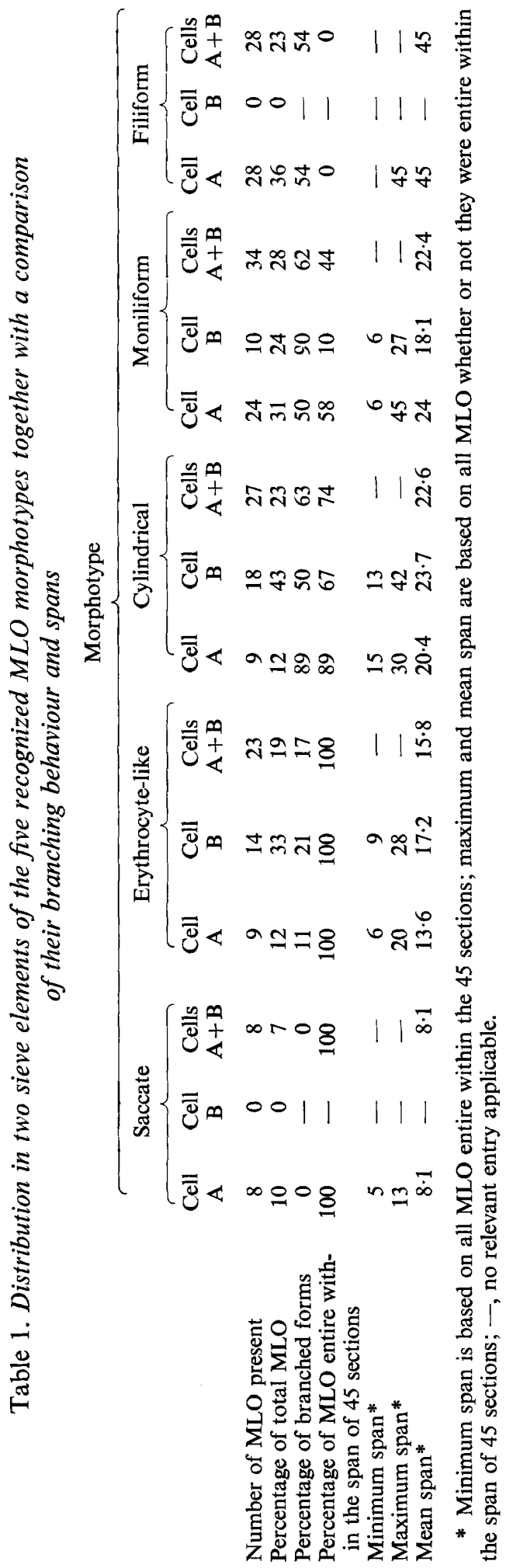



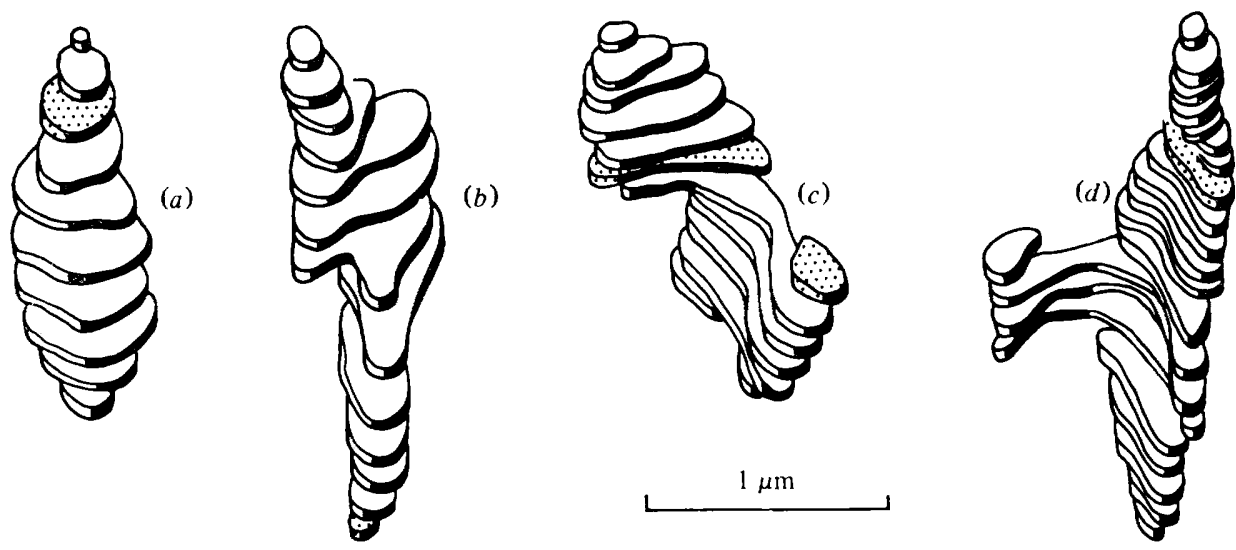

Fig. 4. Reconstructional drawings of representative saccate organisms. The shaded profiles are those which appeared in the middle section of the relevant set of serial sections.

different morphotypes. Volume is a more suitable parameter. The saccate organisms ranged in volume from 9.5 al (i.e. $9 \cdot 5 \times 10^{-18}$ l) to 107 al; these data are compared with those obtained for the other morphological classes in Table 2.

Erythrocyte-like organisms. These were characterized by an approximately discoid central region which was centrally concave or biconcave and peripherally toroidal, the whole structure being reminiscent of the human erythrocyte. At their simplest, erythrocytelike organisms consisted solely of such a disc (Fig. 6a) and approximately one-third of the organisms in this class were of this form. The remaining erythrocyte-like organisms carried one or more approximately cylindrical appendages. One or two appendages were usual (Fig. $6 b, c, d$ ) but organisms with up to five were identified, giving rise to complex structures (Fig. 6e).

Profiles typical of erythrocyte-like organisms are shown in Fig. 7, and together these comprise the organism represented in Fig. 7(m). Figure 7(a) shows a diffuse profile which is associated with a skimming section of an organism, in this instance the edge of the toroidal disc. The sausage-shaped profiles in Fig. $7(b, c)$ become progressively more dumbbell-shaped as the central concavity is traversed (Fig. $7 d, e$ ) returning to sausageshaped profiles (Fig. $7 f, g$ ) before merging into the circular profiles of the appendage (Fig. $7 h, i, j, k$ ). The organism is completed by a skimming section (Fig. $7 l$ ).

Within the plane of sectioning, measurements of erythrocyte-like organisms (made across the disc at the widest point) varied from 200 to $920 \mathrm{~nm}$. The typanum at the central concavity could be up to $80 \mathrm{~nm}$ wide but in most organisms the membranes were closely opposed and measured only $18 \mathrm{~nm}$ across. Perpendicular to the plane of sectioning the seven simplest discoid forms varied in length from $460 \mathrm{~nm}$ to $1.28 \mu \mathrm{m}$ (mean $0.91 \mu \mathrm{m}$ ). Where appendages were present, the overall MLO lengths ranged from $825 \mathrm{~nm}$ to $2 \cdot 1 \mu \mathrm{m}$ (mean $1.75 \mu \mathrm{m}$ ). Like the saccate organisms, linear dimensions showed great variation. Table 2 summarizes volume determinations for these organisms.

Cylindrical organisms. Characteristically, MLO assigned to this class were moderately long and more or less uniform in diameter throughout their length (Fig. $8 a$ ). The majority of cylindrical organisms were complete within the set of serial sections and were therefore less than $3.5 \mu \mathrm{m}$ long. The range of lengths determined are set out in Fig. 13. The mean diameter of each of the cylindrical organisms ranged between 121 and $216 \mathrm{~nm}$ (mean $161 \mathrm{~nm}$ ). Branching was recorded in $63 \%$ of the cylindrical organisms (Table 1) giving rise to $\mathrm{X}$ and $\mathrm{Y}$ forms (Fig. $8 b, c$ ). The shape at the branch-point closely resembled that of the human thumb and forefinger including the intervening web of tissue. Thus, the usually circular profiles at the base of a branch became successively elliptical, sausage- 


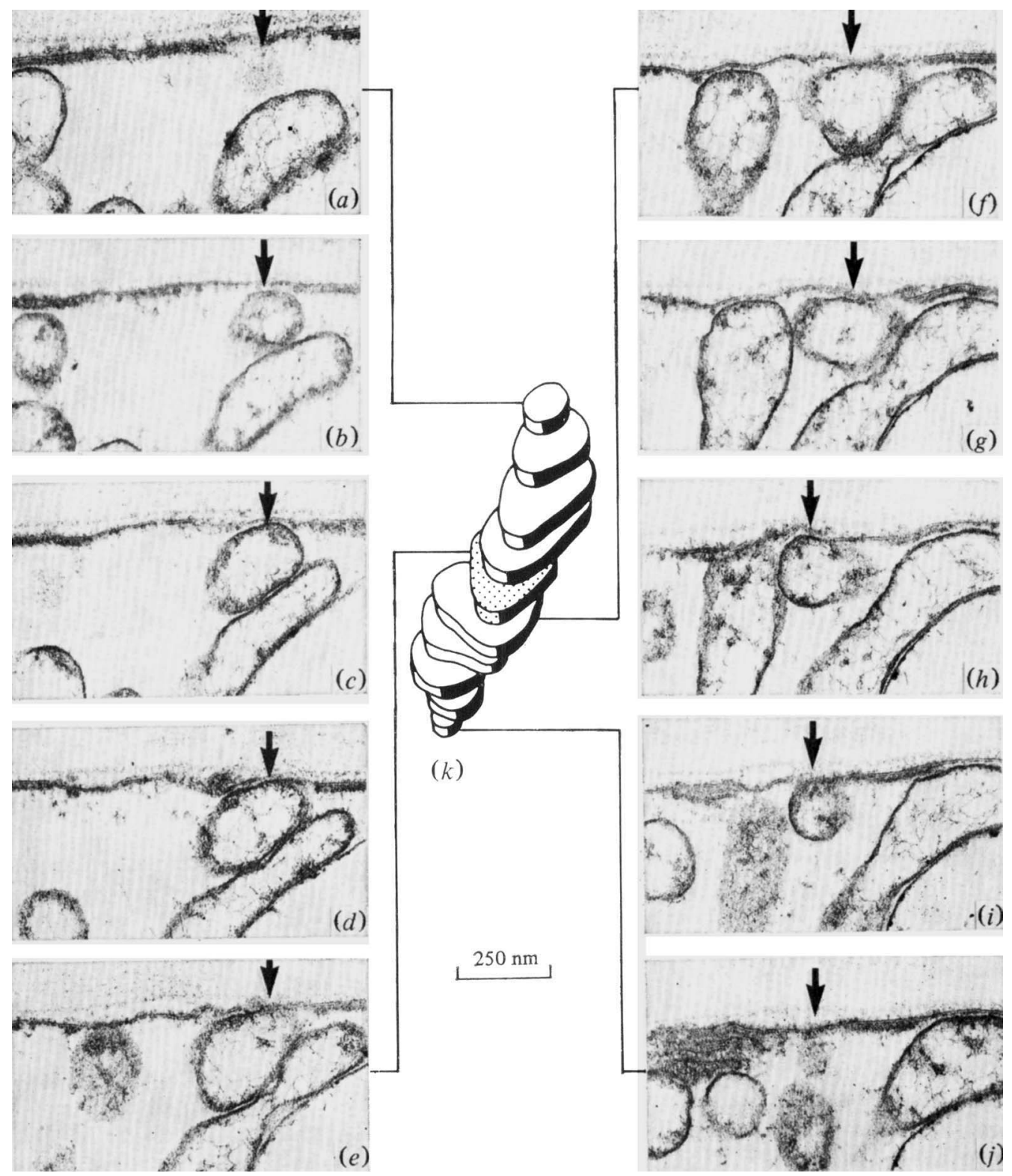

Fig. 5. The ten MLO profiles ( $a$ to $j$ ) which together comprise the saccate organism shown $(k)$. The shaded profile in $k$ is also shown in Fig. 1.

shaped and then dumbbell-shaped as the depth of the branch-point was traversed, leading finally to the circular profiles of the two arms.

Where cylindrical organisms terminated within the set of serial sections the terminations were swollen, almost clavate, being approximately $60 \mathrm{~nm}$ greater in diameter than the remainder of the organism.

For those complete cylindrical organisms observed, the volumes ranged from $41 \cdot 1$ to 116.8 al (Table 2).

Moniliform organisms. As the name implies, the organisms within this class consisted of swollen nodes linked by narrower isthmuses arranged in simple or branched filaments (Figs 9 and 10i). There were differences in the degree of constriction at isthmuses; thus, 
Table 2. Volumes of the five MLO morphotypes recognized

\begin{tabular}{lrcccc} 
& \multicolumn{5}{c}{ Morphotype volume (al) } \\
\cline { 2 - 4 } & Saccate & $\begin{array}{c}\text { Erythrocyte- } \\
\text { like }\end{array}$ & Cylindrical & Moniliform & Filiform \\
Minimum & 9.5 & 38.5 & $41 \cdot 1$ & $19 \cdot 4$ & $10 \cdot 5^{*}$ \\
Mean & 55.5 & $84 \cdot 0$ & $73 \cdot 0^{*}$ & $84 \cdot 7^{*}$ & $28 \cdot 7^{*}$ \\
Maximum & 107.1 & $297 \cdot 7$ & $116 \cdot 8$ & $205 \cdot 6^{*}$ & $77 \cdot 7^{*}$
\end{tabular}

* The volume shown includes data for organisms whose span exceeded that of the 45 sections and it is therefore an underestimate.
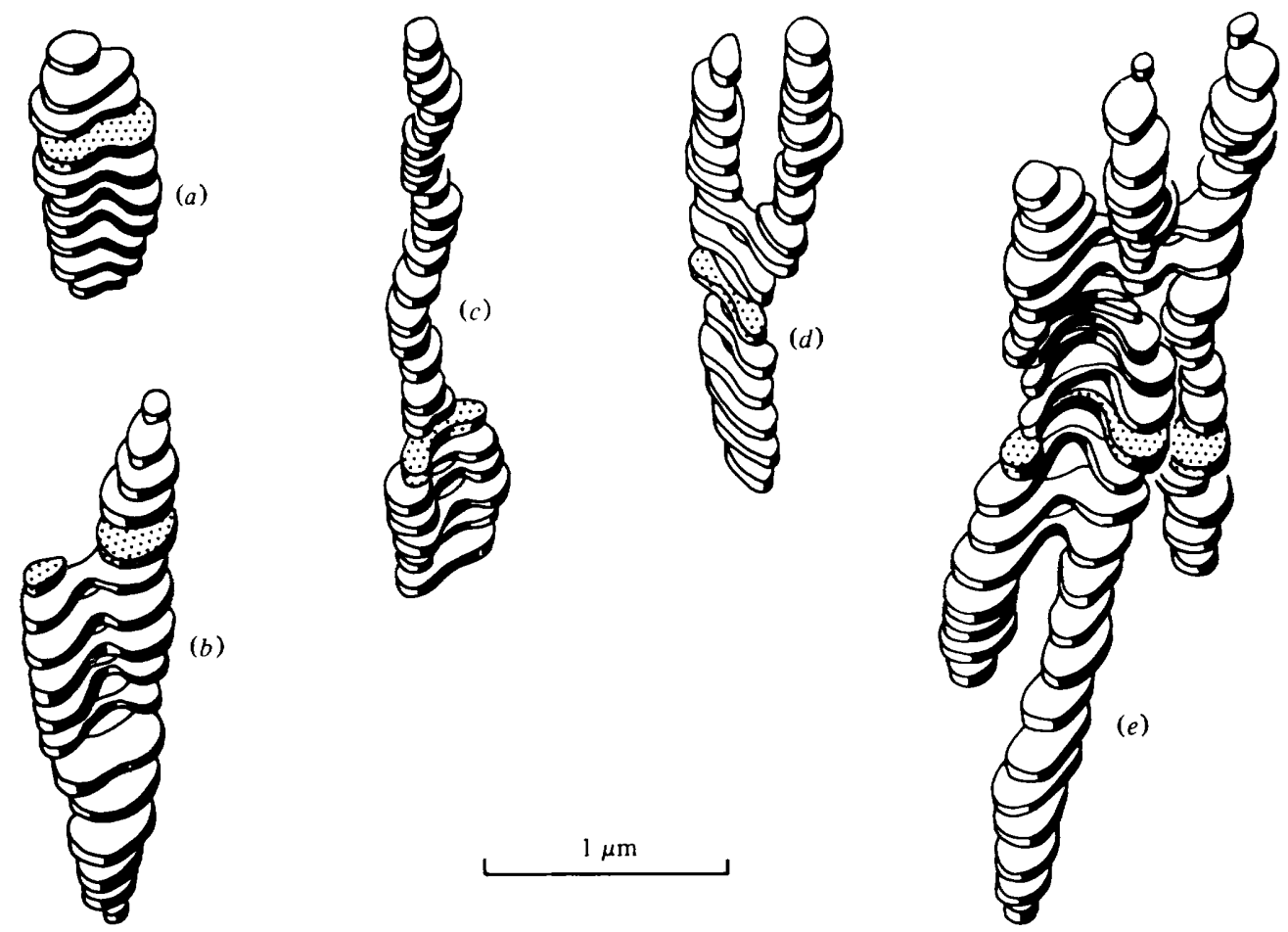

Fig. 6. Reconstructional drawings of representative erythrocyte-like organisms. The shaded profiles are those which appeared in the middle sections of the appropriate set of serial sections; those in $b$ and $e$ are highlighted in Fig. 2.

organisms could be classified as strongly moniliform (Figs $9 a, b$ and $10 i$ ) or weakly moniliform (Fig. $9 c, d$ ). Moniliform organisms were generally longer than cylindrical organisms with $56 \%$ extending out of the series of sections. The range of lengths recorded is summarized in Fig. 13. The mean node diameters for all organisms ranged from 140 to $320 \mathrm{~nm}$ but within any individual organism the range was not so wide (Fig. 11). Where a node was terminal it was usually 50 to $60 \mathrm{~nm}$ larger in diameter than the mean diameter of all nodes in that filament (Fig. 11). Isthmus diameters for strongly moniliform MLO ranged from 18 to $26 \mathrm{~nm}$. The comparative figures for weakly moniliform organisms were 40 to $96 \mathrm{~nm}$.

The characteristic morphology of these organisms was associated with profile shapes such as those illustrated in Fig. 10. The approximately circular profiles in Fig. $10(a)$ are across the widest points of the two nodes and in the successive figures (Fig. 10b,c) the reduction in profile diameter is apparent as the mid-point of the isthmus is traversed (Fig. 10c). A gradual increase in profile diameter (Fig. 10d,e,f) indicates the adjacent node. 

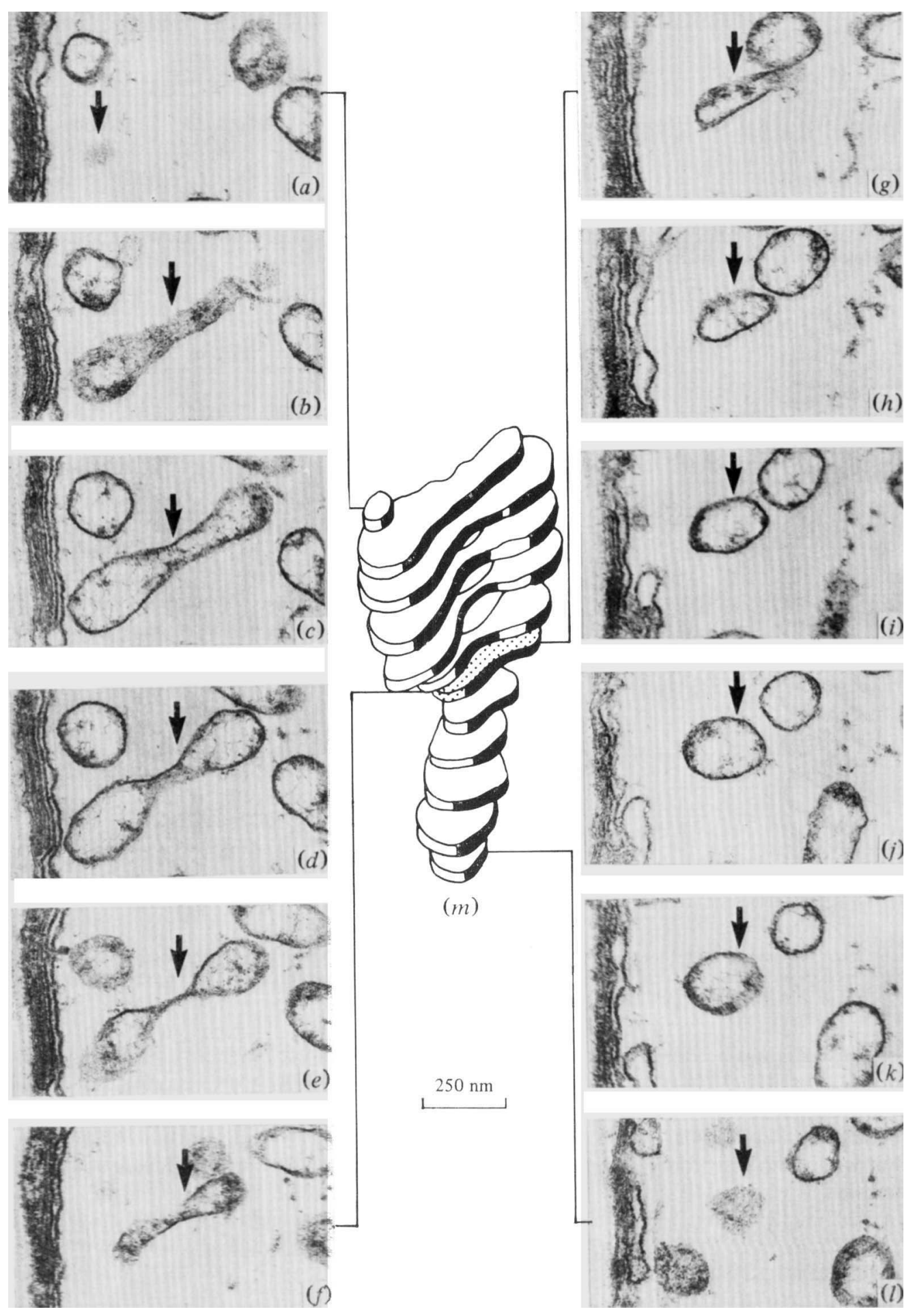

Fig. 7. The 12 MLO profiles ( $a$ to $l$ ) which together comprise the erythrocyte-like organism shown $(m)$. The shaded profile in $m$ is also shown in Fig. 2 . 

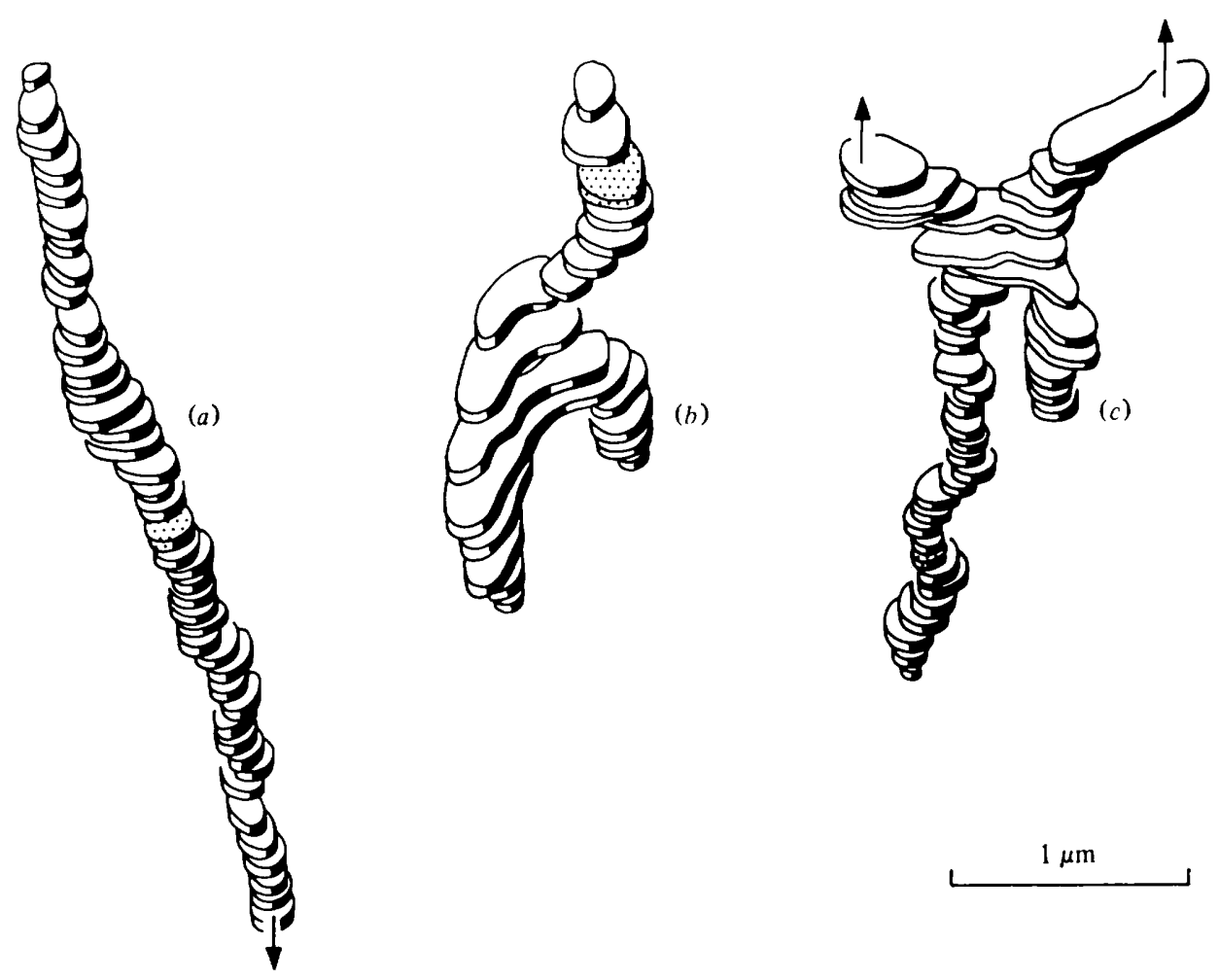

Fig. 8. Reconstructional drawings of representative cylindrical organisms. The shaded profiles are those which appeared in the middle sections of the appropriate set of serial sections; that in $c$ is highlighted in Fig. 2. Arrowed terminal profiles indicate that an organism passed out of the set of serial sections at that end.

Additionally, Fig. $10(e, f)$ shows the profiles seen when the plane of sectioning passes longitudinally through two adjacent nodes. The extreme slenderness of the isthmus is apparent since in each case it appears in only one $75 \mathrm{~nm}$ thick section and there is no trace of it in the sections on either side.

Branching was recorded in $62 \%$ of the moniliform organisms. Branch-points did not involve a modification of the usual form, being mediated through isthmoid connections (Figs $9 a, b, c$ and $10 i$ ).

Clearly complete data on the volumes of these organisms cannot be quoted because so many were incomplete (Fig. 13) but estimates are presented in Table 2.

Filiform organisms. These organisms were longer than all the other morphotypes; none were complete within the $3.5 \mu \mathrm{m}$ of tissue sectioned. Each organism was more or less constant in diameter along its length. The diameters of the 28 MLO (Fig. 13) ranged from 72 to $120 \mathrm{~nm}$ about a mean of $86 \mathrm{~nm}$, with the diameter of individual organisms rarely varying by more than $15 \mathrm{~nm}$.

Approximately half the filiform organisms (Table 1) were unbranched, each being represented by a single circular profile in each of the 45 serial sections (Fig. 12a). These unbranched filaments could represent quite considerable lengths of an individual organism, e.g. the $U$ shaped MLO in Fig. 12(b) was approximately $6.5 \mu \mathrm{m}$ long.

Where branching was observed within the set of serial sections considerable complexity of form was possible (Fig. 12c, $d, e$ ). Organisms such as that shown in Fig. 12(e) ramified through the $3.5 \mu \mathrm{m}$ of sieve element studied being represented by four profiles in the middle 

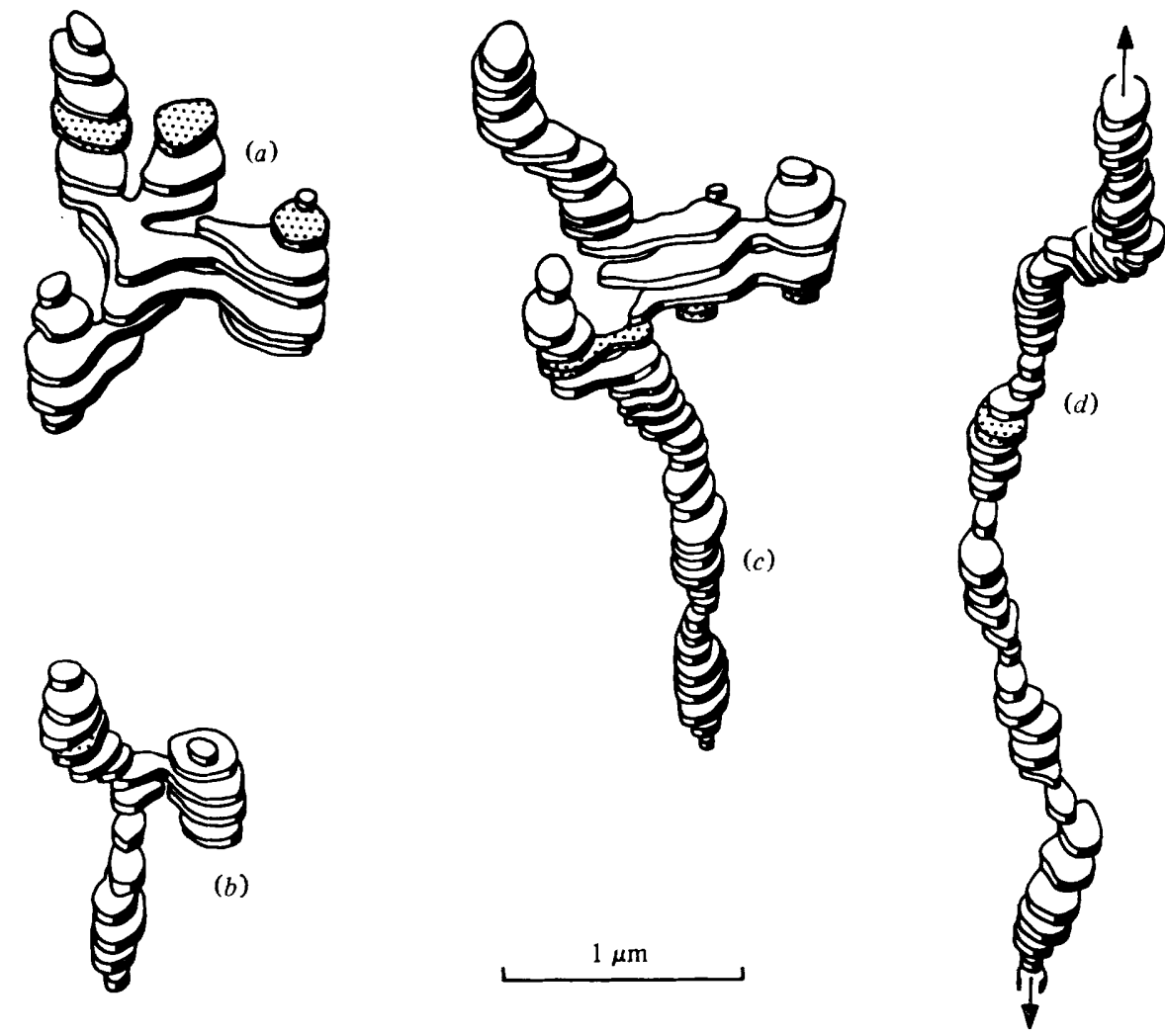

Fig. 9. Reconstructional drawings of representative moniliform organisms. The shaded profiles are those which appeared in the middle sections of the appropriate set of serial sections; those in $a$ and $c$ appear in Fig. 1 and that in $b$ in Fig. 2. Arrowed terminal profiles indicate that an organism passed out of the set of serial sections at one or both ends.

section (Fig. 1) and 208 separate profiles in all. For this one organism we recorded $16.4 \mu \mathrm{m}$ of its total length.

In sections, filiform organisms presented a range of profile shapes which varied as a function of the orientation of the organism to the plane of sectioning. Where the plane of sectioning was exactly at $90^{\circ}$ to the filament, circular profiles with clearly defined membranes were apparent. These were translated into successively more elongated profiles as the orientation of the organism came to lie along the plane of sectioning; e.g. the shaded profiles in Fig. 12(c,e).

Branches were sharply defined (Fig. $12 c, d, e$ ) and often at approximately right angles to the main axis of the filament and were usually associated with a slight constriction of the filament. Where a branch of a filiform organism terminated within the set of serial sections the termination was clavate. Estimates of the volume of filiform organisms are given in Table 2 .

\section{Dimensions of organisms}

Figure 13 compares the mean diameter and lengths for each of the filamentous organisms in cell A (Fig. 1). Saccate and erythrocyte-like organisms have been excluded because their mean diameters cannot be defined. For each filiform or cylindrical organism represented in Fig. 13 the mean diameter was determined from measurements made across profiles in every fourth section of the series. The only exception to this procedure was the omission of readings made across terminations (which were clavate) or branch-points (which were 


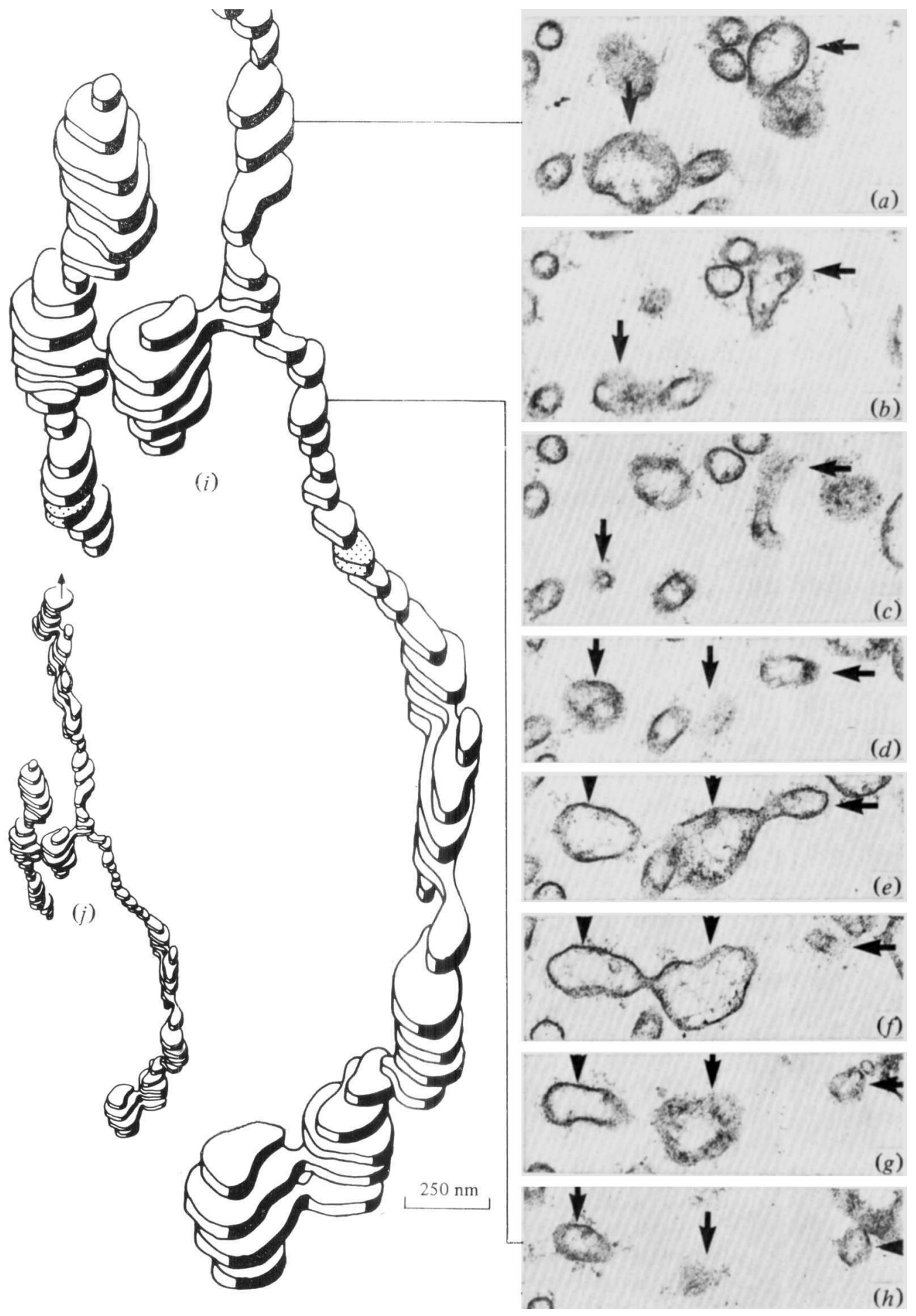

Fig. 10. Eight of the MLO profiles ( $a$ to $h$ ) which comprise part of the moniliform organism which is shown intact $(j)$. The shaded profiles in $i$ are also shown in Fig. 1. 


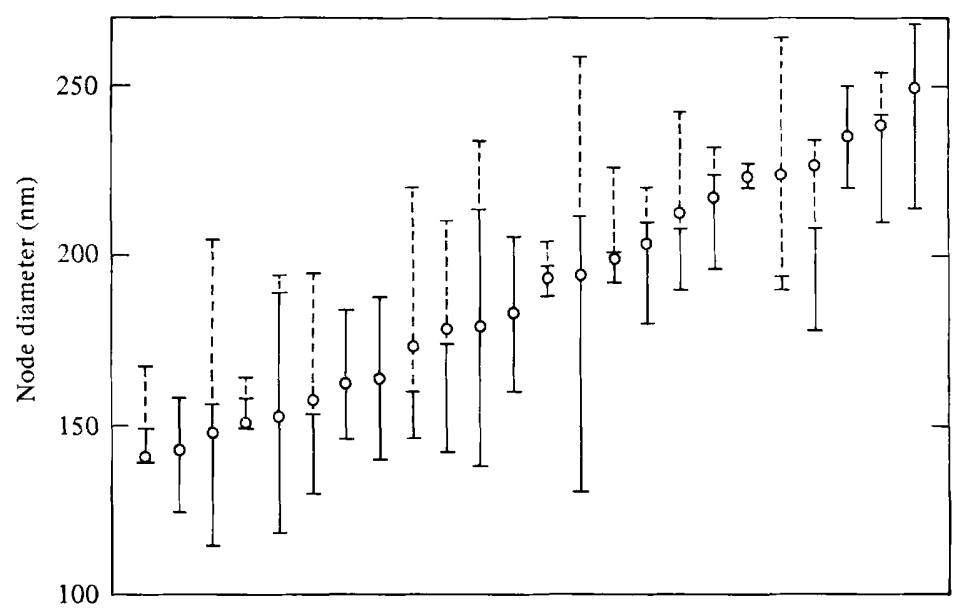

Fig. 11. The mean node diameter (open circles), the range of interstitial node diameters (solid lines) and the diameters of terminal nodes (dotted lines) for each of the 24 moniliform MLO in cell A (Fig. 1). Where no terminal node diameter is indicated the organism consisted of two or three nodes or it did not terminate within the span of the serial sections.

irregularly shaped). For moniliform organisms the diameter presented is the mean of measurements made across all of the nodes of the individual organisms.

With respect to their dimensions, Fig. 13 shows that filiform organisms fell within a group which was quite distinct from the groups of cylindrical and moniliform organisms. With two exceptions, all MLO classed as filiform on the basis of morphological characters lay within the pool having mean diameters of between 60 and $115 \mathrm{~nm}$ and a total recorded length in excess of $2 \cdot 1 \mu \mathrm{m}$. By contrast, all cylindrical MLO were enclosed within the pool having mean diameters between 120 and $220 \mathrm{~nm}$ and lengths of between 1.0 and $3 \mu \mathrm{m}$. Moniliform MLO varied more in their dimensions than the other classes; the mean diameter of nodes ranged between 140 and $248 \mathrm{~nm}$ (Fig. 11) and their length was in excess of $0.825 \mu \mathrm{m}$. In Fig. 13, two moniliform MLO lie outside the perimeter of the moniliform group. This arose because, although we believed them to be joined to other moniliform organisms, the connection was too tenuous and oblique to the plane of sectioning for continuity to be claimed.

\section{Profile shape and ultrastructure: their relationship to MLO morphology}

The profiles, the outlines of which have been used to reconstruct and define the MLO morphotypes, can now be re-examined, with the advantage of hindsight, to show how mycoplasmal morphology can be rationally inferred from ultrathin sections.

The most revealing feature is the limiting membrane because its ultrastructure varies according to its orientation within the section with respect to the electron beam. In an ultrathin section a membrane will only reveal its trilamellar construction when it is parallel with the electron beam. Where membranes lie obliquely to the beam the trilamellar construction is not resolved and instead the membrane appears to be diffuse.

This effect is most easily demonstrated by reference to filamentous organisms. A transverse section through a filamentous organism (Fig. 14a) viewed with an electron beam parallel with its long axis will appear to be circular with the membrane sharply defined (Fig. 14b). A filamentous organism lying obliquely to the same beam (Fig. 14c) presents an approximately elliptical profile with sharply defined membranes only at the edges, otherwise the membranes are diffuse (Fig. 14d). For similarly orientated sections the proportion of sharply defined membranes and the extent of the diffuse membranes are related to the 

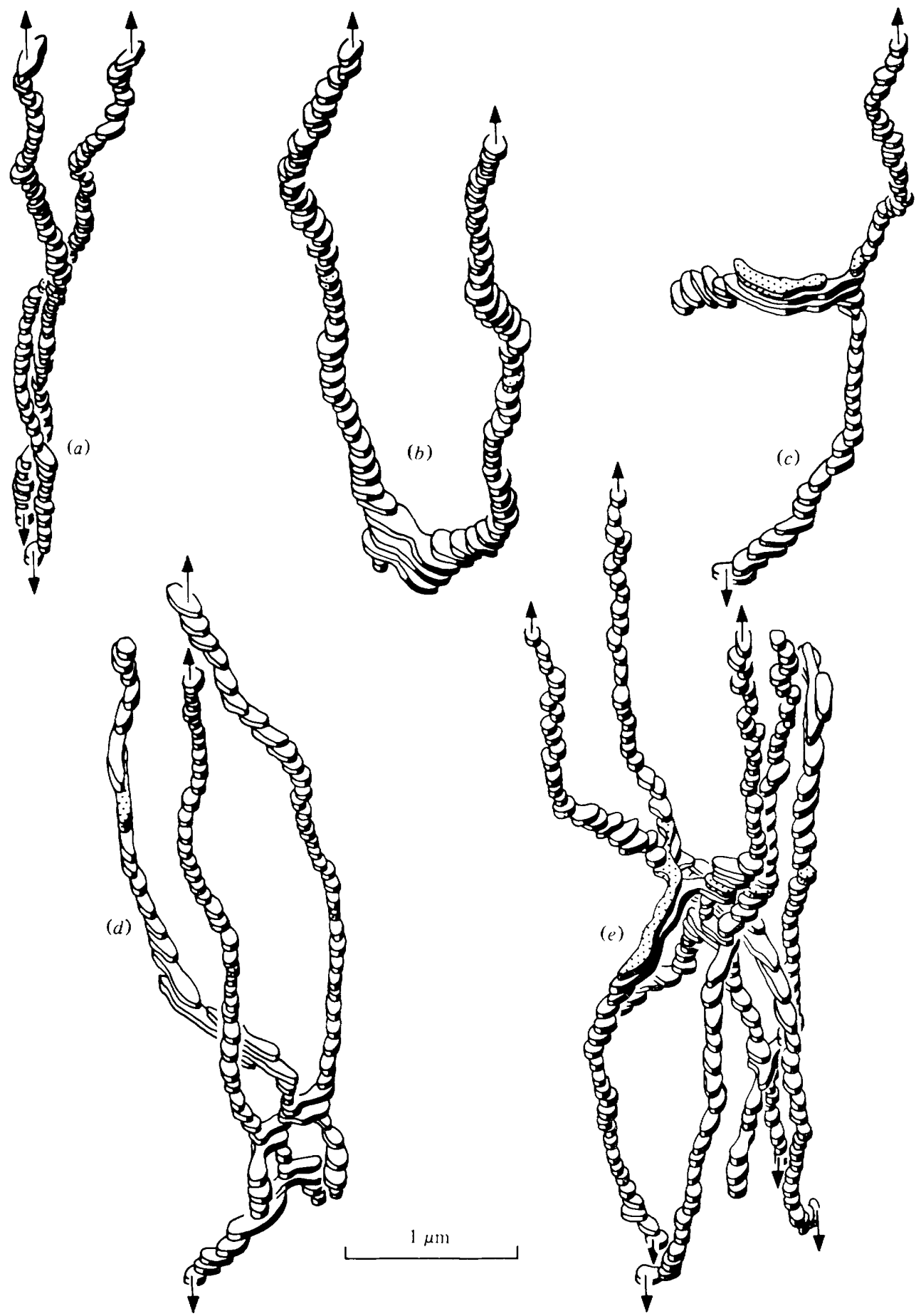

Fig. 12. Reconstructional drawings of representative filiform organisms. The shaded profiles are those which appeared in the middle sections of the appropriate set of serial sections; the four in $e$ are highlighted in Fig. 1 as are the two in $b$. Arrowed terminal profiles indicate that an organism passed out of the set of serial sections at one or both ends. 


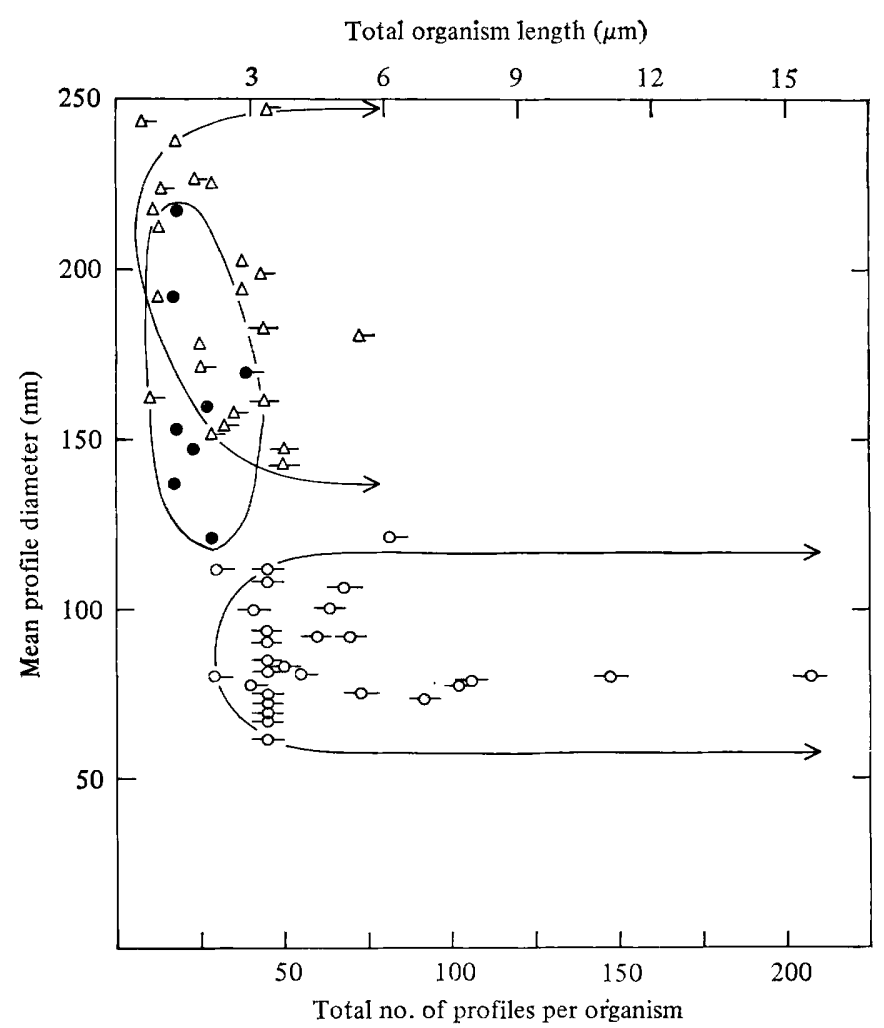

Fig. 13. Mean profile diameters and organism lengths for each of the cylindrical $(\bullet)$, moniliform $(\triangle)$ and filiform $(O)$ MLO in cell A (Fig. 1). Organisms were either complete $(\bullet, \triangle)$ or passed out of the set of 45 serial sections at one end $(O,-, \Delta)$ or both ends $(-O,-\Delta)$.

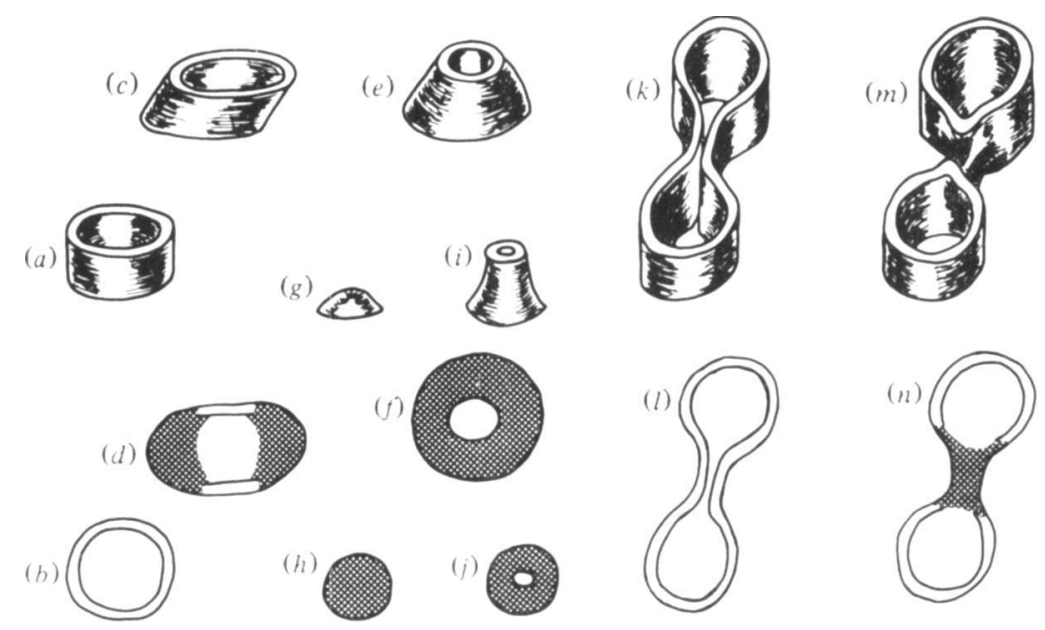

Fig. 14. The shapes of MLO within the thickness of an ultrathin section $(a, c, e, g, i, k, m)$ and their corresponding appearance in electron micrographs $(b, d, f, h, j, l, n)$. Figures are not to scale. 
obliqueness of the organisms to the imaging electron beam. Thus, the membranes of very oblique MLO would appear to be almost entirely diffuse. In our study profiles of the types so far described were the most common because most organisms were filamentous or had parts that were filamentous (e.g. the appendages of erythrocyte-like organisms).

We observed elliptical and sausage-shaped profiles where the membranes were resolved as trilamellar for the entire perimeter. It can be deduced, for the reasons already outlined, that these profiles must have been exactly transverse to the electron beam and it follows that they must have been discoid regions of MLO. Such deduction is supported by the reconstructions of saccate and erythrocyte-like organisms.

Profiles where none of the membrane could be resolved as trilamellar were always associated with changing shape or dimension of an organism. An approximately circular profile with a uniformly diffuse membrane (Fig. $14 h$ ) results from a section close to the termination of a filament or towards one pole of a spherical organism (Fig. $14 \mathrm{~g}$ ). The section immediately adjacent to the termination had an approximately circular profile with a diffuse membrane annulus surrounding an electron transparent centre (Fig. 14e, $f$ ). The shape of the terminal slice always exactly fitted the clear space at the centre of the annulus in the penultimate section. Figure $14(j)$ also shows a diffuse membrane annulus surrounding an electron transparent centre; however, this diagram represents the appearance of an isthmoid connection linking two nodes of a moniliform organism where the plane of sectioning was at right angles to the two nodes (Fig. 14i). These profiles were differentiated from those near terminations because they rarely exceeded $100 \mathrm{~nm}$ in diameter e.g. Fig. 10(c).

Finally we consider the significance of the appearance of membranes in dumbbell-shaped profiles. Trilamellar membranes at the dumbbell constriction imply that the membranes are perpendicular to the plane of sectioning. These profiles (Fig. 14l) can only be generated by sections within the branch-points of cylindrical organisms or sections across the central concavity of erythrocyte-like organisms (Fig. 14k). When such sections lie obliquely to the electron beam, they appear to have a uniformly diffuse membrane. Dumbbell-shaped profiles are also generated from median sections between two nodes of moniliform organisms (Fig. $14 n$ ) but because the isthmoid connection (Fig. $14 m$ ) is contained within the section thickness, its membranes appear to be diffuse although the sections through the nodes on either side of it are orientated so as to allow resolution of their membrane ultrastructure e.g. Fig. $10(f)$.

\section{DISCUSSION}

Boatman \& Kenny (1970) used the technique of serial ultrathin sectioning allied to reconstructions using plasticine to describe the morphology of Mycoplasma felis in culture. The largest organism illustrated was approximately $1 \mu \mathrm{m}$ long and, within the context of the classification of MLO we have given, the organisms were saccate, erythrocyte-like and cylindrical. Boatman (1973b) also figures a plastic sculpture derived from the morphology of $M$. pneumoniae. The author does not indicate how the sculpture was derived but its morphology is most nearly like that of filiform organisms.

Short ribbons of ten or fewer serial sections have been used in attempts to elucidate the morphology of the MLO associated with peach X-disease (MacBeath et al., 1972), hydrangea virescence (Hearon et al., 1976), albino disease of Prunus avium L. (Florance \& Cameron, 1978) and the agent of phloem necrosis of elm after transmission to Vinca rosea L. (Braun, 1977). These studies have all indicated that the MLO were more complex in form than a cursory examination of single sections would have at first indicated. Only Florance \& Cameron (1978) attempted reconstructions of MLO from their serial sections using stereophotography of registered electron micrographs on sheet film. The stereophotographs figured show a pattern of entwined organisms which are either saccate or filamentous. The filamentous organisms appear to be either cylindrical or moniliform according to our classification. Hearon et al. (1976) illustrate filiform organisms but, unlike 
those in coconut roots, many of the filiform MLO show regular constrictions producing 'beaded chains'. Filamentous organisms, some nearly $5.5 \mu \mathrm{m}$ long, were reported by MacBeath et al. (1972) and in most cases these organisms were orientated with their long axes parallel to the sieve tubes. Our observations confirm this parallel alignment of filamentous MLO. Although Braun (1977) was not principally concerned with MLO morphology, he did prepare ribbons of five to eight serial sections and within these spans many MLO were incomplete and suggested the presence of filaments.

Following its successful application in elucidating the structure of spiroplasma (Davis \& Worley, 1973), stereoscopy of electron micrographs of $300 \mathrm{~nm}$ thick sections of the phloem of Erodium cicutarium showing yellows disease symptoms revealed that the associated MLO were filamentous or occasionally erythrocyte-like (Graf et al., 1978).

Scanning electron microscopy of critical point dried freeze-fractured sieve elements provides a different approach to elucidating the form of MLO and has been applied by Petzold et al. (1977) and Haggis \& Sinha (1978). The organisms visualized are spherical, filamentous and erythrocyte-like.

Previous workers using transmission electron microscopy of serial sections or thick ultramicrotome sections have provided a partial picture of the morphology of MLO in vivo. It is apparent that for a more complete reconstruction of individual organisms the ribbons of sections must be much longer than five to ten sections. From our studies, it is clear that $\mathrm{MLO}$ in vivo can be far more complex than a traditional interpretation of sectioned organisms would have at first suggested. The forms defined are analogous to those frequently reported for Mycoplasma species in vitro (Anderson, 1969) and this is perhaps further evidence of the taxonomic affinity of the MLO with the mycoplasmas. It should be noted that we never encountered any helical forms such as those associated with the spiroplasmas.

It is recognized that the results presented are based on organisms fixed at one moment in time. A concomitant of the absence of any cell wall is that mycoplasmas and MLO have the ability to change form and in Mycoplasma hominis this change can be both rapid and sometimes reversible (Bredt, 1970; Bredt et al., 1973). We would expect that the organisms in the phloem of coconut palms affected by lethal yellowing would exhibit at least some of the same behaviour.

Apart from the dynamic changes in the morphology of individual organisms, the morphology of mycoplasmas in vitro also follows a sequence of changes associated with the age of cultures. Under optimal conditions, spherical, rod-shaped and dumbbell-shaped bodies predominate in exponential phase cultures, and whilst these forms are still present during stationary phase, other forms such as filaments, beaded chains and lobed bodies are also present (Razin et al., 1967; Furness, 1970; Robertson et al., 1975b). Very late stationary phase cultures are marked by the presence of beaded chains and small coccoid forms some having the dimensions of elementary bodies (Furness, 1970; Robertson et al., $1975 \mathrm{~b}$ ). Translating this understanding of mycoplasmal morphology in vitro to the morphology of the MLO we have described suggests that the MLO were fixed during stationary phase when conditions for growth were sub-optimal (Robertson et al., 1975b). It is not surprising, therefore, that we did not associate dumbbell-shaped profiles with organisms undergoing binary fission. On the other hand, our results do not indicate the presence of beaded chains or elementary bodies such as those reported by Hearon et al. (1976). This suggests that the MLO in palm roots were not in very late stationary phase. The differences in the morphology of MLO reported by us and others is evidence that the various observations were made at different stages in the development of the organisms in the host sieve elements. The primary infection of an individual sieve element is probably by coccoid bodies which reproduce initially by binary fission, whilst conditions are optimal. Later, as conditions become less conducive to growth, the more complex morphotypes appear. 
It has frequently been claimed that dumbbell-shaped profiles represent organisms preserved whilst undergoing binary fission (Worley, 1970; Maramorosch et al., 1970; Maniloff \& Morowitz, 1972; Hirumi \& Maramorosch, 1973). We recorded many instances of dumbbell-shaped profiles; these were most usually parts of erythrocyte-like organisms but they could also be parts of moniliform or branched cylindrical organisms. In no instance was a dumbbell-shaped profile associated with an organism exhibiting binary fission.

Prominence has been given to the presence of small circular profiles 80 to $120 \mathrm{~nm}$ in diameter, the so-called elementary bodies, which appear in electron micrographs of phloem from diseased plants or in cultures of mycoplasmas. Occasionally these profiles may be arranged in beaded chains. This emphasis stems from a theory of mycoplasmal reproduction which suggests the intracellular production of propagules, i.e. elementary bodies (Freundt, 1969; Anderson, 1969). The reproductive role of such structures has now been discredited on the grounds that a sphere of diameter less than 250 to $300 \mathrm{~nm}$ cannot contain a genome of sufficient size to sustain the existence of a mycoplasma and by analogy an MLO (Morowitz \& Wallace, 1973; Robertson et al., 1975b). We never found an organism which could have been described as an elementary body. Instead, the circular profiles 80 to $120 \mathrm{~nm}$ in diameter present in our sections were usually parts of the most extensive MLO found, i.e. the filiform MLO.

Circular profiles greater than $100 \mathrm{~nm}$ in diameter predominated amongst the profiles available for analysis. Previously, these might have been interpreted as representing simple spherical or filamentous forms. It is apparent that, whilst this may be true, such a simple interpretation belies the degree of complexity that MLO composed almost entirely of such profiles can achieve. Simple approximately spherical organisms were rare, as were simple unbranched filaments.

Sausage-shaped profiles were associated with those parts of filamentous organisms lying almost parallel to the plane of sectioning. However, it cannot be assumed that this profile shape always indicates filamentous form. Erythrocyte-like organisms and branched cylindrical organisms can also be indicated by sausage-shaped profiles.

Finally, we recorded instances of three-lobed profiles. It has been suggested that lobed profiles are associated with budding and therefore reproduction. Our evidence does not deny a reproductive role but it does show that such lobed profiles can be parts of basically filamentous organisms.

The profile shapes that have formed the basis of our analysis are not different from those reported previously from sectioned mycoplasmas either from culture or in vivo. However, the morphologies of the organisms of which they are a part range from simple to very complex. We would suggest a more cautious interpretation of MLO and mycoplasmal morphology when these are based on inferences from single thin sections. This is especially so when proposing mechanisms of reproduction since none of our evidence supports binary fission or the existence of elementary bodies.

In any study of mycoplasmal morphology the possibility of inducing artifacts is ever present. We believe that we have minimized these effects in our preparative procedures in which long pieces of roots were used and any trimming was carried out after fixation. Further, the host tissue itself acts as a control for the detection of gross artifact, and in the roots used here the tissues were well preserved. All the morphotypes we have described were included in two cells and one of those cells contained representative MLO of each of the five groups recognized. We believe that the forms described genuinely represent the morphology of the reconstructed MLO.

This work was carried out as part of the Lethal Yellowing of Coconuts Research Scheme (R 3098) funded by the United Kingdom Ministry of Overseas Development, The Government of Jamaica and The Coconut Industry Board, Jamaica. 


\section{REFERENCES}

ANDERSON, D. R. (1969). Ultrastructural studies of mycoplasmas and L-phase of bacteria. In The Mycoplasmatales and the L-phase of Bacteria, pp. 365-401. Edited by L. Hayflick Jr. New York: Appleton-Century-Crofts.

Beakbane, B. A., Slater, C. H. W. \& Posnette, A. F. (1972). Mycoplasmas in the phloem of coconut, Cocos nucifera L., with lethal yellowing disease. Journal of Horticultural Science 47, 265.

BERNSTEIN-ZIV, R. (1971). The effect of hypotonic solutions on the morphology of cells of $\mathrm{Myco}$ plasma gallisepticum. Canadian Journal of Microbiology 17, 1203-1205.

Boatman, E. S. (1973a). Morphology and ultrastructure of mycoplasmas. Annals of the New York Academy of Sciences 225, 172-180.

Boatman, E. S. (1973b). Morphological heterogeneity of the Mycoplasmatales. Journal of Infectious Diseases 127 (supplement), S12-S14.

Boatman, E. S. \& KenNy, G. E. (1970). Threedimensional morphology, ultrastructure, and replication of Mycoplasma felis. Journal of Bacteriology 101, 262-277.

BoATMAN, E. S. \& KeNNy, G. E. (1971). Morphology and ultrastructure of Mycoplasma pneumoniae spherules. Journal of Bacteriology 106, 1005-1015.

BrAUN, E. J. (1977). A freeze-etch and thin-section study of mycoplasmas in Vinca rosea phloem. Journal of Ultrastructural Research 60, 44-51.

BREDT, W. (1970). Experimentelle Untersuchungen über Morphologie und Vermehrung der beim Menschen vorkommenden Mycoplasmen unter besondere Berücksichtigung von Mycoplasma hominis. Zeitschrift für medizinische Mikrobiologie und Immunologie 155, 248-274.

Bredt, W., Heunert, H. H., Hofling, K. H. \& MilthaleR, B. (1973). Microcinematographic studies of Mycoplasma hominis cells. Journal $o_{\text {, }}$ Bacteriology 113, 1223-1227.

Cole, R. M., Tully, J. G., Popkin, T. J. \& Bové, J. M. (1973). Morphology, ultrastructure, and bacteriophage infection of the helical mycoplasmalike organism (Spiroplasma citri gen.nov., sp.nov.) cultured from 'stubborn' disease of citrus. Journal of Bacteriology 115, 367-386.

Davis, R. E. \& Worley, J. F. (1973). Spiroplasma: motile, helical organism associated with corn stunt disease. Phytopathology 63, 403-408.

Davis, R. E., Worley, J. F., Whitcomb, R. F., IshiJima, T. \& Steere, R. L. (1972). Helical filaments produced by a mycoplasma-like organism associated with corn stunt disease. Science 176, 521-523.

Doi, Y., Teranka, M., Yora, K. \& Asuyma, H. (1967). Mycoplasma- or PLT-like microorganisms found in the phloem elements of plants infected with mulberry dwarf, potato witches' broom, aster yellows or paulowinia witches' broom. Annals of the Phytopathological Society of Japan 33, 259-266. [Translated from the original Japanese in Review of Plant Protection Research (1969) 2, 84-88.]

DuNN, R. F. (1972). Graphic three-dimensional representations from serial sections. Journal o, Microscopy 96, 301-307.
Florance, E. R. \& Cameron, H. R. (1978). Threedimensional structure and morphology of mycoplasmalike bodies associated with albino disease of Prunus avium. Phytopathology 68, 75-80.

FreundT, E. A. (1960). Morphology and classification of the PPLO. Annals of the New York Academy of Sciences 79, 312-325.

FreundT, E. A. (1969). Cellular morphology and mode of replication of the mycoplasmas. In The Mycoplasmatales and the L-phase of Bacteria, pp. 281-315. Edited by L. Hayflick Jr. New York: Appleton-Century-Crofts.

FurNESS, G. (1970). The growth and morphology of mycoplasmas replicating in synchrony. Journal of Infectious Diseases 122, 146-158.

Graf, M. E., Ehrenfeld, R. \& Davis, R. E. (1978). Stereo electronmicroscopy of mycoplasmalike organisms in Erodium cicutarium with yellows disease symptoms. Plant Disease Reporter 62, 535-538.

HagGis, G. H. \& Sinha, R. C. (1978). Scanning electron microscopy of mycoplasmalike organisms after freeze fracture of plant tissues affected with clover phyllody and aster yellows. Phytopathology 68, 677-680.

Hearon, S. S., Lawson, R. H., Smith, F. F., MCKenzie, J. T. \& Rosen, J. (1976). Morphology of filamentous forms of a mycoplasmalike organism associated with hydrangea virescence. Phytopathology 66, 608-616.

Hirumi, H. H. \& Maramorosch, K. (1973). Ultrastructure of the aster yellows agent: mycoplasmalike bodies in sieve tube elements of Nicotiana rustica. Annals of the New York Academy of Sciences 225, 201-222.

HorNe, R. W. (1972). Comparison between the structure of animal and plant mycoplasmas: extracellular and intracellular morphology. In $C I B A$ Foundation Symposium on Pathogenic Mycoplasmas, pp. 39-57. Edited by K. Elliot \& J. Birch. Amsterdam: Associated Science Publishers.

Hunt, P., DabeK, A. J. \& Schuiling, M. (1974). Remission of symptoms following tetracycline treatment of lethal yellowing infected coconut palms. Phytopathology 64, 307-312.

LEMCKE, R. M. (1972). Osmolar concentrations and fixation of mycoplasmas. Journal of Bacteriology 110, 1154-1162.

MacBeath, J. H., Nyland, G. \& Spurr, A. R. (1972). Morphology of mycoplasmalike bodies associated with peach X-disease in Prunus avium. Phytopathology 62, 935-937.

Maniloff, J. \& Morowitz, H. J. (1972). Cell biology of the mycoplasmas. Bacteriological Reviews 36, 263-290.

Maramorosch, K., Granados, R. R. \& Hirumi, H. (1970). Mycoplasma diseases of plants and insects. Advances in Virus Research 16, 135-193.

Markham, P. G., Townsend, R., Bar-JosePh, M., Daniels, M. J., Plaskitt, A. \& Meddins, B. M. (1974). Spiroplasmas are the causal agent of citrus little leaf disease. Annals of Applied Biology 78, 49-57.

McCoy, R. E. (1972). Remission of lethal yellowing 
in coconut palm treated with tetracycline antibiotics. Plant Disease Reporter 56, 1010-1021.

Morowitz, H. J. \& Wallace, D. C. (1973). Genome size and the life cycle of the mycoplasma. Annals of the New York Academy of Sciences 225, 62-73.

Parthasarathy, M. V. (1974). Niycoplasma-like organisms associated with lethal yellowing disease of palms. Phytopathology 64, 667-674.

Petzold, H., Marwitz, R., Özel, M. \& GoszdZIEWSKI, P. (1977). Versuche zum raterelektronmikroskopischen Nachweis von mykoplasmaähnlichen Organismen. Phytopathologische Zeitschrift 89, 237-248.

Plavsic-Banjac, B., Hunt, P. \& Maramorosch, K. (1972). Mycoplasmalike bodies associated with lethal yellowing disease of coconuts. Phytopathology 62, 298-299.

RazIN, S. (1978). The mycoplasmas. Microbiologica Reviews 42, 414 470.

Razin, S., Cosenza, B. J. \& Tourtellotte, M. E. (1967). Filamentous growth of mycoplasma. Annals of the New York Academy of Sciences 143, 66-72.

REID, N. (1974). Ultramicrotomy. In Practical Methods in Electron Microscopy, vol. 3, p. 288. Edited by A. M. Glauert. Amsterdam: NorthHolland Publishing Company.

Robertso v, J., Gomersall, M. \& Gill, P. (1975a). Effect of preparatory techniques on the gross morphology of Mycoplasma hominis. Journal of Bacteriology 124, 1019-1022.

Robertson, J., Gomersall, M. \& Gill, P. (1975b). Mycoplasma hominis: growth, reproduction and isolation of small viable cells. Journal of Bacteriology 124, 1007-1018.

Saglio, P., L'Hospital, M., Laflèche, D., Dupont, G., Bové, J. M., Tully, J. G. \& Freundt, E. A.
(1973). Spiroplasma citri gen. and sp.n.: a mycoplasma-like organism associated with 'stubborn' disease of citrus. International Journal of Systematic Bacteriology 23, 191-204.

SpurR, A. R. (1969). A low viscosity epoxy resin embedding medium for electron microscopy. Journal of Ultrastructural Research 26, 31-43.

Tully, J. G. (1978). Biology of the mycoplasmas. In Mycoplasma Infection of Cell Cultures, pp. 1-33. Edited by G. J. McGarrity, D. G. Murphy \& W. N. Nichols. New York: Plenum Publishing Corporation.

Turner, A. W. (1935). A study of the morphology and life cycles of the organism of Pleuropneumonia contagiosa boum (Borrelomyces peripneumonia nov.gen.) by observation in the living state under dark-ground illumination. Journal of Pathology and Bacteriology 41, 1-32.

Venable, J. H. \& Coggershall, R. (1965). A simplified lead citrate stain for use in electron microscopy. Journal of Cell Biology 25, 407-408.

WATERs, H. \& HunT, P. (1978). Serial sectioning to demonstrate the morphology of a plant mycoplasma-like organism. Zentralblatt für Bakteriologie, Parasitenkunde, Infektionskrankheiten und Hygiene 241, 225.

WolANSKI, B. S. (1973). Negative staining of plant agents. Annals of the New York Academy of Sciences 225, 223-235.

Wolanski, B. S. \& Maramorosch, K. (1970). Negatively stained mycoplasmas: fact or artifact. Virology 42, 319-327.

WORLEY, J. F. (1970). Possible replicative forms of a mycoplasma-like organism and their location in aster yellows diseased Nicotiana and aster. Phytopathology 60, 284-292. 